\title{
Polymorphic Diversity of UBX Domain D from cDNA Isolated from Pectoral Muscle of Korean Native Chicken
}

\author{
Sangsoo Sun ${ }^{1}$, Abdolreza Kamyab ${ }^{2}$ and Jeff Firman ${ }^{2,}$ \\ ${ }^{I}$ Department of Animal Science, Chonnam National University, Gwangju 500-757, Korea \\ ${ }^{2}$ University of Missouri, Columbia, MO 65203, USA
}

\begin{abstract}
The objectives of this study are to identify specific functional genes which are related with growth and protein structure of the pectoral muscle of Korean native chicken. Pectoral muscle was isolated from three Korean native chickens (KNC, red brown, 12 months old, $2.41 \pm 0.24 \mathrm{~kg}$ ) and three Cornish chickens (16 month old, $2.76 \pm 3.0 \mathrm{~kg}$ ). The subtraction cDNA library was prepared in PCR4 Blunt-TOPO vector. The DNA sequence homology was compared with other breeds and species in GenBank. A clone NDS-81 was found to be unique for the DNA sequence homology with UBX family. Their partial sequence has high homology (98\%) with chicken UBX domain D. Chicken UBX domain has chicken (93\%), cattle (68\%), dog (67\%), mouse (64\%) and, human (63\%) nucleotide sequence homology. Several regions were mutated from $\mathrm{T}$ in chicken to C or G in the NDS-81 clone. The first site is LAD in chicken, but it was expressed as (L)RM in clone NDS-81. In this site, amino acids were changed from Ala to Arg, and from Asp to Met. The second site was changed from ER (Arg) in chicken to ED (Asp) in clone NDS-81. They are both containing functional side chains and play an important role in binding other proteins. Therefore, the clone NDS-81 could be a different candidate gene for the UBX family gene and could related with pectoral muscle structure of Korean native chicken.

(Key words : UBX domain D, Korean native chicken, cDNA, muscle growth)
\end{abstract}

\section{INTRODUCTION}

Genetic resources of native animals would be important in world markets for future bio-industry. Meat quality is especially closely related to the DNA expression of muscle proteins $(\mathrm{Ca}-$ ravatti et al., 1982, Sun et al., 2006). Large-scale genomic and cDNA sequencing projects have revealed thousands of new genes whose open reading frames (ORFs) are highly conserved during vertebrate evolution, but whose precise cellular functions remain unclear. Only full-length cDNAs unambiguously define the boundaries of the transcription units within whole-genome assemblies. Cloned full-length cDNAs are also of immense practical value to complement mutant phenotypes and artificially express the encoded protein (Caldwell et al., 2005).

Korean native chicken $(\mathrm{KNC})$ is a conserved breed for pedigree, family line, and improving economic value. Commercial broilers have low preference and palatability although they have good economic value with high growth rate. Therefore, the KNC needs to be conserved for unique taste and meat quality (Sang et al., 2003). Also, KNC may have strong resistance against some pathogenic microorganisms (personal communication).
Ubiquitin regulator-X (UBX, erasin) is a discrete protein domain that binds $\mathrm{p} 97 /$ valosin-containing protein (VCP), a molecular chaperone involved in diverse cell processes, including endoplasmic-reticulum-associated protein degradation (ERAD). UBXD2 is highly conserved in mammals compared to poultry and other species. Erasin is an integral membrane protein of the endoplasmic reticulum and nuclear envelope with both its $\mathrm{N}$ and C-termini facing the cytoplasm or nucleoplasm (Liang et al., 2006). A widely expressed protein containing UBX (ubiquitin-like) domains was identified as a substrate of SAPKs (stressactivated protein kinases) (McNeill et al., 2004). These proteins may be involved in skeletal muscle growth and structure.

The objectives of this study were to identify specific functional genes which are related with animal growth and structure of pectoral muscle in Korean native chicken.

\section{MATERIALS AND METHODS}

\section{Animals}

Experimental animals were described in a previous paper (Sun et al., 2006). Three Korean native chickens (KNC, red

\footnotetext{
† To whom correspondence should be addressed : sssun@chonnam.ac.kr
} 
brown, 12 months old, $2.41 \mathrm{~kg} \pm 0.24$ ) and three Cornish chickens (16 month old, $2.76 \mathrm{~kg} \pm 3.04$ ) were obtained from the Daejeon branch of the National Livestock Research Institute, Korea. Pectoral muscles were dissected and frozen immediately in liquid nitrogen. Total RNA was isolated by RNA isolation kit (Clonetech, Korea). mRNA was analyzed by the methods of Poly (A)+ purification using PolyATract mRNA isolation System (Promega, USA).

\section{2. mRNA Subtraction and Cloning}

Two breed mRNAs were subtracted by the methods of subtractive suppression hybridization. mRNA was subtracted by suppression hybridization method using PCR-select cDNA Subtraction Kit. Cloned cDNA were inserted into PCR4 Blunt-TOPO vector. The cloned vector was transformed in TOP 10 electroporation cells. The cDNA was then used as a probe to screen $0.5 \times 10^{6}$ lysate plates. Specific clones were constructed by the subtraction from cDNA of Korean native chicken to cDNA of Cornish chicken.

\section{3. cDNA Library Preparation}

Isolated RNA was used Sub-Lib DNA (Eugentech, Korea). To select E. coli contained incorporated plasmid, E. coli $(0.1$ $\mathrm{mL}$ ) was spread on LB/AMP/ KAN/ X-Gal plates and were incubated overnight at $37^{\circ} \mathrm{C}$. The cultured colony was adjusted to $1 \times 10^{4}$ cfu per $10 \mathrm{ng}$ of vector DNA. From cultured colony, the single white colony was inoculated in LB/AMP/KAN, and was incubated for $16 \sim 18 \mathrm{hrs}$ in shaking $(170 \mathrm{rpm})$ incubator until $0.6 \sim 0.8$ O.D. value at $37^{\circ} \mathrm{C}$. The cultured liquid $(817 \mathrm{uL})$ was mixed with $80 \%$ glycerol $(183 \mathrm{uL})$, and then this culture stock was stored in $-70^{\circ} \mathrm{C}$. This culture stocks $(1.0 \mathrm{~mL})$ were centrifuged in $1.5 \mathrm{~mL}$ tube at $3,000 \mathrm{rpm}$ for $15 \mathrm{~min}$, and the $E$. coli cell pellet was collected.

Vector ligation was used with $80 \mathrm{ng}$ of cDNA and $10 \mathrm{ng}$ of PCR4 Blunt-TOPO vector. cDNA inserted vector was transformed into TOP 10 electroporation cells (Invitrogen). The cell pellet was dissolved completely in $250 \mathrm{uL}$ resuspension buffer $(\mathrm{P} 1)$ in $1.5 \mathrm{~mL}$ tube, and then the plasmid was isolated using QIAprep Miniprep kit (Invitrogen). The mixture was gently mixed with 250 uL lyses buffer (P2), and incubated for 4 min at RT. 250 $\mathrm{uL}$ Neutralization buffer (N3) was added, incubated for $5 \mathrm{~min}$, and then centrifuged for $10 \mathrm{~min}$ at $10,000 \mathrm{rpm}$. Supernatant was transferred into a binding column tube and was centrifuged 60 sec, and filtered liquid was discarded. PE buffer $(750 \mathrm{uL})$ was added into the binding column tube and it was centrifuged for $1 \mathrm{~min}$ at $12,000 \mathrm{rpm}$. The binding column tube was completely dried without ethanol. The binding column tube was connected into $1.5 \mathrm{~mL}$ tube, $50 \mathrm{uL}$ Elution buffer was added in the middle, rested for $1 \mathrm{~min}$, and centrifuged for $1 \mathrm{~min}$ at 13,000 rpm. The isolated plasmid was digested with restriction enzymes, and the DNA size was identified with electrophoresis. The insert was sequenced (Macrogen, Korea), and the homology was compared with other breeds and species in GenBank.

\section{RESULTS AND DISCUSSION}

Six-hundred fifty nucleotides were sequenced from two-thousand clones. Six unique clones were registered in GenBank. The six clones were NDS-7 (accession no, AY466164, 847 nt), NDS-10 (accession no, EF117324.1, 495 nt), NDS-13 (accession no, EF 117325.1, 452 nt), NDS-22 (accession no, EF117326.1, 1730 nt), NDS-24 (accession no, EF117327.1, 1003 nt), NDS-81 (accession no, EF117328.1, 612 nt). A clone NDS-7 was actin-like protein and was published (Sun et al., 2006).

A clone NDS-81 was also derived from cDNA subtraction of pectoral muscle of Korean native chicken. This clone is very specific for the DNA sequence homology with UBX domain. NDS-81 has 612 nucleotides, and the translated region is 17 593 nt. The untranslated region (UTR) was expressed underlined in italics (Fig. 1). Every ten nucleotides were marked by dot. This partial sequence has high homology $(98 \%)$ with chicken UBX domain D (Liang et al., 2006). They reported that the erasin, the new name of UBX family, may be involved in human disease but it is related with the structure of chicken pectoral muscle. Therefore, the expression of DNS-81 could change threedimensional structure of skeletal muscle and could modify texture of chicken breast muscle.

DNA sequence was compared with other organisms. The clone NDS-81 is matched (327 nt) with chicken (Gallus gallus) cDNA clone ChEST293i14 (Boardman et al., 2004). In humans (Homo sapiens), it may be related with GAS7 (growth arrestspecific protein) and/or MIH (molt-inhibiting hormone) (Devaraj and Natarajan, 2006) and PAC clone RP5-968I16 from 7 (Arnett et al., 1998). Also, the sequence will be a fragment of 


\section{GCGTGGTCGC.GGCCGAGGTA.CAGTTACCTC.TGCTGCATTA.TTCAGCCAGG.CTCTGATCAC. \\ 61 CAAAATTAGT.TGAAAATATT.TTTGTTACAG.CAGATTACAG.CACAGCACAC.ATTTGCTCTC. \\ 121 TAAGATCACA.CTAGGTAAGA.ATGGTAGTGC.ATCCAGATAT.TGCTGATTAC.ATTTTGTCTA. \\ 181 GTTCTGCCTG.TGTGTAGCTT.TCAGTCAGTA.ATAAACTAAT.TTGAACTTGT.GCTTCTGATA. \\ 241 GCATTTGTTT.GCTCATTCTT.GAGCCGTCCA.TTAGGTGTAG.CAGCAGTTTT.ACAGTCGTCA. \\ 301 TCAGGAGCTT.TCATTGCTAA.CAGTCTAAAA.GGTTCGGTTG.TTTTCCGAAG.TCTCTGAACA. \\ 361 ACAACAGCAT.TTTGCAACTT.TGCTTCCTGT.AGTGTGAGCG.TCTCATCTTG.CAGTTCTCGA. \\ 421 AAGGGCAGCG.AAGTAGTCAG.CATGAAGGGA.ACACCTCCCT.CTGATCCTTG.ATACTTTGTT. \\ 481 ATGAAGTCTC.TGACATGGCT.TATTCTGTGG.GAAACGTTGA.ACTTCTGAAT.ATCCTCTCCC. \\ 541 ATCCGCTACC.AGATCTGGAT.GTTAGTGATA.GGCTCCAAAT.CATTTAAAG.GTACCTGCCC. \\ 601 GGGGCGGNCG.CTC}

Fig. 1. Partial cDNA sequence (612 bases) of clone NDS-81 derived from Korean native chicken. The translated region is $17 \sim 593$ nt and untranslated region was expressed boxed italic character.

undulin-2 in humans (Just et al., 1991). In chimpanzees (Pan troglodytes), a similar sequence was reported from chromosome 7 clone RP43-9F6. Another possibility was suggested that our clone is similar with hypothetical protein in mouse (Mus musculus) (Kawai et al., 2002). Haptoglobin was partially related with clone NDS-81 in rabbits (Oryctolagus cuniculus). However, all sequence ho-mology was not representing the clone NDS-81 information.

Nucleotide sequence of NDS-81 was compared with chicken UBX domain D4 (Fig. 2). Several regions were mutated from $\mathrm{T}$ in chicken to $\mathrm{C}$ or $\mathrm{G}$ in NDS-81. It may have severe structural modification due to not making a $\mathrm{H}$-bond between $\mathrm{T}$ and $\mathrm{A}$. They are going to make G-C linkage for their three-dimensional structure. The late regions were point deleted and then can not be translated or expressed to different protein. These specific sites are expressed in the gray box in Fig. 2. These compounds will have an effect on GLUT system for glucose transport in mouse model (Schertzer et al., 2009; Kim et al., 2011).

Chicken UBX domain containing D4 (UBXD4) and mRNA for hypothetical protein from clone 10c14 ND were compared. They are 98\% (571/579 nt) homology of amino acid sequence (Fig. 3). Chicken UBX domain has chicken (93\%), cattle (68\%), $\operatorname{dog}(67 \%)$, mouse (64\%) and human (63\%) amino acid sequence homology. Clone NDS-81 match with Gallus gallus UBX domain containing 4 (UBXD4) mRNA (Caldwell et al., 2005). A similar sequence was found to in the UBX domain containing 4 in cattle, dog, monkey, and rat (Carim-Todd et al., 2001).

In this comparison, we found several major mutated sites. Those sites are very conservative among other species including chicken. Therefore, two sites would play an important role in muscle gene expression. The first site is LAD in chicken, but it was expressed as (L)RM in clone NDS-81. In this site, amino acids were changed from Ala to Arg, and from Asp to Met. The second site was changed from ER (Arg) in chicken to ED (Asp) in clone NDS-81. They both contain functional side chains and play an important role in binding other proteins and protein structure. A large number of cDNA inserts were sequenced from a high-quality library of chicken breast muscle cDNAs. Comparisons to public gene databases indicate that the cDNA collection represents new gene, full-length transcripts. This resource defines the structure and the coding potential of a large fraction of chicken growth gene. The changed structure will also modify functional characteristics (Albrecht et al., 2004). Therefore, we conclude that the clone NDS- 81 could be a different candidate gene for UBX family gene and could related with pectoral muscle structure of Korean native chicken.

\section{ACKNOWLEDGMENTS}

This study was financially supported by Chonnam National University, 2006. 


\begin{tabular}{|c|c|}
\hline NDS-10 & GTACAGTTACCTCTGCTGCATTATTCAGCCAGGCTCTGATCACCAAAATTAGTTGAAAAT \\
\hline Chicken & GTACAGTTACCTCTGCTGCATTATTCAGCCAGGCTCTGATCACCAAAATTAGTTGAAAAT \\
\hline NDS-10 & ATTTTTGTTACAGCAGATTACAGCACAGCACACATTTGCTCTCTAAGATCACACTAGGTA \\
\hline Chicken & ATTTTTGTTACAGCAGATTACAGCACAGCACACATTTGCTCTCTAAGATCACACTAGGTA \\
\hline NDS-10 & AGAATGGTAGTGCATCCAGATATTGCTGATTACATTTTGTCTAGTTCTGCCTGTGTGTAG \\
\hline Chicken & AGAATGGTAGTGCATCCAGATATTGCTGATTACATTTTGTCTAGTTCTGCCTGTGTGTAG \\
\hline NDS-10 & СTTTCAGTCAGTAATAAACTAATTTGAACTTGTGCTTCTGATAGCATTTGTTTGCTCATT \\
\hline Chicken & CTTTCAGTCAGTAATAAACTAATTTGAACTTGTGCTTTTCATAGCATTTTTTTGCTCATT \\
\hline NDS-10 & CTTGAGCCGTCCATTAGGTGTAGCAGCAGTTTTACAGTCGTCATCAGGAGCTTTCATTGC \\
\hline Chicken & СTTGAGCCGTCCATTAGGTGTAGCAGCAGTTTTACAGTCGTCATCAGGAGCTTTCATTGC \\
\hline NDS-10 & TAACAGTCTAAAAGGTTCGGTTGTTTTCCGAAGTCTCTGAACAACAACAGCATTTTGCAA \\
\hline Chicken & TAACAGTCTAAAAGGTTCGGTTGTTTTCCGAAGTCTCTGAACAACAACAGCATTTTGCAA \\
\hline NDS -10 & стTTGCTTCCTGTAGTGTGAGCGTCTCATCTTGCAGTTCTCGAAAGGGCAGCGAAGTAGT \\
\hline Chicken & CTTTGCTTCCTGTAGTGTGAGCGTCTCATCTTGCAGTTCTCGAAAGGGCAGCGAAGTAGT \\
\hline NDS-10 & CAGCATGAAGGGAACACCTCCCTCTGATCCTTGATACTTTGTTATGAAGTCTCTGACATG \\
\hline Chicken & CAGCATGAAGGGAACACCTCCCTCTGATCCTTGATACTTTGTTATGAAGTCTCTGACATG \\
\hline NDS-10 & GСTTATTCTGTGGGAAACGTTGAACTTCTGAA-TATCCTCT_CCCATCCGCT_ACCAGAT \\
\hline Chicken & GCTTATTCTGTGGGAAACGTTGAATTTCTGAATTATCCTCTC्CCCATCCGCTÄACCAGAT \\
\hline NDS-10 & CTGGATGTTAGTGATAGGCTCCAAATCATTTAAAGGTAC \\
\hline Chicken & CTGGATGTTAGTGATAGGCTCCAAATCATTTAAGGGTAC \\
\hline
\end{tabular}

Fig. 2. Nucleotide sequence comparison of NDS-81 (576 nt) and mRNA of chicken UBX domain containing 4 (UBXD4).

\begin{tabular}{|c|c|}
\hline NDS-81 & VPLNDLEPITNIQIW?RMGEDI ?QKFNVSHRISHVRDFITKYQGSEGGVPFMLTTSLPFR \\
\hline Chicken & VPLNDLEP ITNIQ IWLADGERI I QKFNVSHRISHVRDF ITKYQGSEGGVPFMLTTSLPFR \\
\hline Cattle & VPLNNLEP ITNIQIWLANGKRIVQKFNISHRISH I KDF IEKYQGSQRSPPFSLATALPFL \\
\hline Dog & VQLNNLEP ITNVQ IWLANGKRIVQKFNISHRISH I KDF IEKYQGSQRSPPFSLATALPFL \\
\hline Mouse & VSLNNLEPITRIQIWLANGERTVQRFNVS HRVSH I KDF IEKYQGSQRSPPFALATALPFL \\
\hline Human & VPLNNLEPITNIQIWLANGKRIVQKFNITHRVSH I KDF IEKYQGSQRSPPFSLATALPVL \\
\hline Frog & 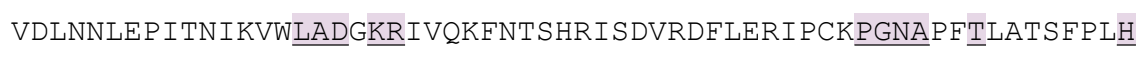 \\
\hline Catfish & VELDEA I P ITC IQIWLADGRRIVQRFN IS HRIS DVQGFVEKAQS S SSPFI ITTSLPFREL \\
\hline NDS -81 & ELQDETLTLQEAKLLNAVVVQRLRKT TEEPFRLLAMKAPDDDCKTAATPNGRLKNEQTNAI \\
\hline Chicken & $\underline{E L} \underline{Q} D E T L T L Q E A \underline{K} L Q N A V \underline{V} Q R L R K T \underline{T} E P F R L L A M K A P D D D C K T A A T P N G R L K N E Q K N A M$ \\
\hline Cattle & $\underline{K L L D E T L T L E E A D L Q N A V I I Q R L K K T A E E P F K E L S ~}$ \\
\hline Dog & $\underline{K L L D E T L T L E E A D L Q N A V I I Q R L Q K T \underline{A} E P F R E L S}$ \\
\hline Mouse & $\underline{R} F \underline{L D E T L T L E E A D L K N A V I I Q R L Q K T A E E P F R K L ~}$ \\
\hline Human & 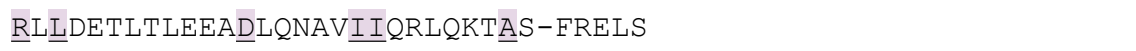 \\
\hline Frog & DLLDESLTLQEADLQNSVIVQKLQKTTEPPRNS \\
\hline Catfish & TQGNLSLEEADITNAVIVQRPVSTQA $\underline{P} F G Q S$ \\
\hline
\end{tabular}

Fig. 3. Comparison of a partial sequence of 192 amino acids from clone NDS-81 with other species. The major sites (478 476, 473 $472,431 \sim 434,417 \sim 416,398 \sim 397 \mathrm{nt})$ of mutated were expressed in box. 


\section{LITERATURE CITED}

Albrecht M, Golatta M, Wüllner U, Lengauer T 2004 Structural and functional analysis of ataxin-2 and ataxin-3. Eur $\mathrm{J}$ Biochem 271(15):3155-3170.

Arnett C, Elliott G, Le TP, Wohldmann P 1998 The sequence of Homo sapiens PAC clone RP5-968I16. Genome Res 8(11): 1097-1108.

Boardman PE, Bonfield JK, Brown WRA, Carder C, Chalk SE, Croning MDR, Davies RM, Francis MD, Grafham DV, Hubbard SJ, Humphray SJ, Hunt PJ, Maddison M, McLaren SR, Niblett D, Overton IM, Rogers J, Scott CE, Taylor RG, Tickle C, Wilson SA 2004 Sequence and comparative analysis of the chicken genome provide unique perspectives on vertebrate evolution. Nature 432(7018):695-716.

Caldwell RB, Kierzek AM, Arakawa H, Bezzubov Y, Zaim J, Fiedler P, Kutter S, Blagodatski A, Kostovska D, Koter M, Plachy J, Carninci P, Hayashizaki Y, Buerstedde JM 2005 Full-length cDNAs from chicken bursal lymphocytes to facilitate gene function analysis. Genome Biol 6(1):R6.

Caravatti M, Minty A, Robert B, Montarras D, Weydert A, Cohen A, Daubas P, Buckingham M 1982 Regulation of muscle gene expression: The accumulation of messenger RNAs coding for muscle-specific proteins during myogenesis in a mouse cell line. J Mol Biol 160:59.

Carim-Todd L, Escarceller M, Estivill X, Sumoy L 2001 Identification and characterization of UBXD1, a novel UBX domain-containing gene on human chromosome 19p13, and its mouse ortholog. Biochim Biophys Acta 1517(2):298-301.

Devaraj H, Natarajan A 2006 Molecular mechanisms regulating molting in a crustacean. FEBS J 273(4):839-846.

Just M, Herbst H, Hummel M, Durkop H, Tripier D, Stein H, Schuppan D 1991 Undulin is a novel member of the fibronectin-tenascin family of extracellular matrix glycoproteins. J Biol Chem 266(26):17326-17332.

Kawai J, Shinagawa A, Shibata K, Yoshino M, Itoh M, Ishii Y, Arakawa T, Hara A, Fukunishi Y, Konno H, Adachi J, Fukuda S, Aizawa K, Izawa M, Nishi K, Kiyosawa H, Kondo S, Yamanaka I, Saito T, Okazaki Y, Gojobori T, Bono H, Kasukawa T, Saito R, Kadota K, Matsuda H, Ashburner M, Batalov S, Casavant T, Fleischmann W, Gaasterland L, Gissi C, King B, Kochiwa H, Kuehl P, Lewis S, Matsuo Y, Ni- kaido I, Pesole G, Quackenbush J, Schriml LM, Staubli F, Suzuki R, Tomita M, Wagner L, Washio T, Sakai K, Okido T, Furuno M, Aono H, Baldarelli R, Barsh G, Blake J, Boffelli D, Bojunga N, Carninci P, de Bonaldo MF, Brownstein MJ, Bult C, Fletcher C, Fujita M, Gariboldi M, Gustincich S, Hill D, Hofmann M, Hume DA, Kamiya M, Lee NH, Lyons P, Marchionni L, Mashima J, Mazzarelli J, Mombaerts P, Nordone P, Ring B, Ringwald M, Rodriguez I, Sakamoto N, Sasaki H, Sato K, Schonbach C, Seya T, Shibata Y, Storch KF, Suzuki H, Toyo-oka K, Wang KH, Weitz C, Whittaker C, Wilming L, Wynshaw-Boris A, Yoshida K, Hasegawa Y, Kawaji H, Kohtsuki S, Hayashizaki Y 2002 Analysis of the mouse transcriptome based on functional annotation of 60,770 full-length cDNAs. Nature 420(6915):563-573.

Kim KH, Kang W, Suh SW, Yang JK 2011 Crystal structure of FAF1 UBX domain in complex with p97/VCP N domain reveals a conformational change in the conserved FcisP touchturn motif of UBX domain. Proteins 79(8):2583-2587.

Liang J, Yin C, Doong H, Fang S, Peterhoff C, Nixon RA, Monteiro MJ 2006 Characterization of erasin (UBXD2): a new ER protein that promotes ER-associated protein degradation. J Cell Sci 119(19):4011-4024.

McNeill H, Knebel A, Arthur JS, Cuenda A, Cohen P 2004 A novel UBA and UBX domain protein that binds polyubiquitin and VCP and is a substrate for SAPKs. Biochem $\mathrm{J}$ 384(2):391-400.

Sang BD, Choi CH, Kim HG, Kim SD, Jang BG, Na JC, Yu DJ, Lee SJ, Lee JH 2003 Effects of strains and enviromental factors on economic traits in Korean native chicken. Korean J Poult Sci 30(4):235-244.

Schertzer JD, Antonescu CN, Bilan PJ, Jain S, Huang X, Liu Z, Bonen A, Klip A 2009 A transgenic mouse model to study glucose transporter 4 myc regulation in skeletal muscle. Endocrinology 150(4):1935-1940.

Shin JH, Kim H, Song KD, Han BK, Park TS, Kim DK, Han JY 2005 A set of testis-specific novel genes collected from a collection of Korean Native Chicken ESTs. Anim Genet 36(4):346-348.

Sun SS, Myung KH, Kuk K, Kim NO 2006 Polymorphic diversity of actin-like protein from cDNA isolated from Korean native chicken. Int J Poult Sci 5(9):863-867.

(접수: 2011. 7. 14, 수정: 2011. 8. 22, 채택: 2011. 8. 29) 